\title{
Postnatal changes in constitutive cyclooxygenase-2 expression in the mice hippocampus and its function in synaptic plasticity
}

\author{
HYO YOUNG JUNG ${ }^{1}$, DAE YOUNG YOO ${ }^{1,2}$, SUNG MIN NAM ${ }^{1,3}$, JONG WHI KIM ${ }^{1}$, \\ WOOSUK KIM $^{1}$, HYUN JUNG KWON ${ }^{4}$, KWON YOUNG LEE ${ }^{5}$, JUNG HOON CHOI ${ }^{5}$, \\ DAE WON KIM ${ }^{4}$, YEO SUNG YOON ${ }^{1,6}$, JE KYUNG SEONG ${ }^{1,6}$ and IN KOO HWANG ${ }^{1,6}$
}

\begin{abstract}
${ }^{1}$ Department of Anatomy and Cell Biology, College of Veterinary Medicine, and Research Institute for Veterinary Science, Seoul National University, Seoul 08826; ${ }^{2}$ Department of Anatomy, College of Medicine, Soonchunhyang University, Cheonan, Chungcheongnam 31151; ${ }^{3}$ Department of Anatomy, College of Veterinary Medicine, Konkuk University, Seoul 05030;

${ }^{4}$ Department of Biochemistry and Molecular Biology, Research Institute of Oral Sciences, College of Dentistry, Gangneung-Wonju National University, Gangneung, Gangwon 25457; ${ }^{5}$ Department of Anatomy,

College of Veterinary Medicine and Institute of Veterinary Science, Kangwon National University, Chuncheon, Gangwon 24341; ${ }^{6}$ Korea Mouse Phenotyping Center, Seoul National University, Seoul 08826, Republic of Korea
\end{abstract}

Received July 18, 2018; Accepted January 9, 2019

DOI: $10.3892 / \mathrm{mmr} .2019 .9867$

\begin{abstract}
Although the expression of cyclooxygenase-2 (COX-2) is closely associated with inflammation in the brain, it is constitutively expressed in the brain, and its expression is regulated by synaptic activity. The present study investigated postnatal expression of COX-2 in the hippocampus in C57BL/6 mice at postnatal days $(\mathrm{P}) 1,7,14,28$, and 56 . In addition, the presented study examined the effects of COX-2 on synaptic plasticity through Arc, phosphorylated cAMP response element-binding protein (pCREB), $N$-methyl-d-aspartate receptor 1 (GluN1), and GluN2A/2B immunohistochemistry, which was performed on COX-2 knockout (KO) and wild-type (WT) mice. Extremely weak COX-2 immunoreactivity was detected in the hippocampal CA1-3 areas in addition to the dentate gyrus at P1. Conversely, COX-2 immunoreactivity was observed in the stratum pyramidale of the CA1-3 regions and in the outer granule cell layer of the dentate gyrus at P7. Additionally, although peak COX-2 immunoreactivity was observed in all hippocampal sub-regions, including the dentate gyrus at P14, it was significantly decreased at P14. Finally, COX-2 immunoreactivity and the distribution pattern seen at P56 in the hippocampal CA1-3 regions were similar to those observed at P28, whereas, they were identified in the inner half of the granule cell layer of the dentate gyrus. The western blot analysis revealed that the COX-2 protein levels
\end{abstract}

Correspondence to: Professor In Koo Hwang, Department of Anatomy and Cell Biology, College of Veterinary Medicine, and Research Institute for Veterinary Science, Seoul National University, 1 Gwanak Road, Seoul 08826, Republic of Korea

E-mail: vetmed2@snu.ac.kr

Key words: cyclooxygenase-2, hippocampus, mice, postnatal development, synaptic plasticity peaked at P14 and were decreased at P28 and P56. Additionally, the number of Arc and pCREB immunoreactive cells as well as GluN1 and GluN2A/2B immunoreactivity of COX-2 KO mice were significantly decreased in the dentate gyrus when compared with that in WT mice. Taken together, the results of the present study suggest that COX-2 serves an important role in synaptic plasticity in the dentate gyrus and changes in the levels of its constitutive expression are associated with the hippocampal dentate gyrus postnatal development.

\section{Introduction}

The hippocampus is one of the most intensely studied brain regions given its function in learning and memory, providing that it is a site of neurogenesis and that it has a unique cellular organization and development (1). In the mouse hippocampus, a small number $(15 \%)$ of granule cells are generated during embryogenesis, while the others are produced within 2 weeks after birth (2-4). Although we demonstrated in previous studies that the structural lamination of the granule cell layer is accomplished by 2 weeks after birth $(4,5)$, maturation was observed at 3 weeks after birth (6).

Cyclooxygenases (COXs) are enzymes that catalyze the production of prostaglandins from the arachidonic acid. Specifically, two COX isoforms similar in their amino acid sequence exist, namely COX-1 and COX-2. While COX-1 is constitutively expressed in cells, although its expression levels vary in different cell types, COX-2 expression is induced by mitogens and it is nearly undetectable in most tissues under normal conditions $(7,8)$. In fact, the arachidonic acid is converted in the cell membrane into prostaglandin $\mathrm{H}_{2}\left(\mathrm{PGH}_{2}\right)$ by COX-2, which is a rate-limiting enzyme in inflammatory processes. Subsequently, it is further metabolized into prostanoids, including $\mathrm{PGE}_{2}$, $\mathrm{PGI}_{2}$, and thromboxane $\mathrm{A}_{2}(9)$, most of which are involved in the inflammatory response; PGE2 is associated with excitatory synaptic transmission by the release of glutamate instead (10). 
For example, brain damage induced by transient forebrain ischemia activates the inflammatory responses by upregulating COX-2 expression and the subsequent increases in prostaglandin synthesis (11). Furthermore, pharmacological or genetic blockade of COX-2 confers neuroprotection against ischemic damage (12). Nevertheless, COX-2 is constitutively expressed in certain tissues, including the brain, thymus, gut, and kidney (13). While constitutive COX-2 is believed to play a major role in homeostatic function, the constitutive expression of neuronal COX-2 is regulated by synaptic activity (14-16). We demonstrated in a previous study that COX-2 immunoreactivity is mainly found in both the granule cells of the dentate gyrus and the pyramidal cells of the hippocampal CA3 region and that COX-2 immunoreactivity is decreased in the hippocampus with age (16). In addition, COX-2 deficiency achieved by genetic and pharmacological inhibition decreased cell proliferation and neuroblast differentiation in the dentate gyrus (17-19). However, although COX-2 mRNA is expressed in the brain, including in the hippocampus (20-22), little is known about COX-2 expression during the structural lamination of the hippocampus and its role in synaptic plasticity. Therefore, in the present study, we investigated the postnatal changes in both COX-2 immunoreactivity and protein levels in the mice hippocampus to observe the localization of constitutive COX-2 during structural lamination. Furthermore, we examined the role of COX-2 in the synaptic plasticity of the hippocampal dentate gyrus using wild-type (WT) and COX-2 KO mice.

\section{Experimental procedures}

Experimental animals. Young male C57BL/6J mice at postnatal days (P) 1, 7, 14, 28, and 56 ( $\mathrm{n}=10$ for each group) were used in the current study. The day of birth was considered day 0 . Litters were culled to a maximum of 7 pups at the day of birth, as described in previous studies (4-6). From any one litter, a maximum of two animals were taken for each age group, ensuring that animals of a given age originated from at least four different litters. To elucidate the role of COX-2 in the hippocampus, COX-2 KO and WT mice (8-week-old) were purchased from Taconic (Hudson, NY, USA). Animal handling and care conformed to the guidelines established by the current international laws and policies (NIH Guide for the Care and Use of Laboratory Animals, NIH Publication No. 85-23, 1985, revised 2011) and were approved by both the Institutional Animal Care and Use Committee (IACUC) of Seoul National University (approval no.: SNU-120210-1 and SNU-140313-1) and Kangwon National University (approval no.: KW-161226-1). All of the experiments were conducted with an effort to minimize the number of animals used and the suffering caused by the procedures employed in the present study.

Tissue processing. Animals from each age group as well as COX-2 KO and WT mice of 12 weeks of age were euthanized with a urethane injection $(1.5 \mathrm{~g} / \mathrm{kg}$ body weight, intraperitoneally, Sigma; Merck KGaA, Darmstadt, Germany). While the brains from each age group were fixed for $24 \mathrm{~h}$ in $10 \%$ neutral buffered formalin at $25^{\circ} \mathrm{C}, \mathrm{COX}-2 \mathrm{KO}$ and WT mice were perfused transcardially with $0.1 \mathrm{M}$ PBS ( $\mathrm{pH}$ 7.4) followed by
$4 \%$ paraformaldehyde in a $0.1 \mathrm{M}$ phosphate-buffer ( $\mathrm{pH} 7.4$ ), as described previously (4-6). Subsequently, their brains were dissected and post-fixed for $12 \mathrm{~h}$ in the same fixative; subsequently, they were dehydrated with graded concentrations of alcohol to be embedded in paraffin. Finally, paraffin-embedded tissues were sectioned on a microtome (Leica Microsystems $\mathrm{GmbH}$, Wetzlar, Germany) into $3-\mu \mathrm{m}$ coronal sections and mounted onto silane-coated slides.

Immunohistochemistry for COX-2, Arc, GluN1, GluN2A/2B, and $p C R E B$. All sections were processed under the same conditions to ensure that the immunohistochemical data would be comparable among the groups, as described in previous studies (4-6). Specifically, they were hydrated and treated with $0.3 \% \mathrm{H}_{2} \mathrm{O}_{2}$ in phosphate-buffered saline (PBS) for $30 \mathrm{~min}$. Thereafter, they were placed in 100-ml jars filled with citrate buffer (pH 6.0) and heated in a 2100-retriever (Prestige Medical, Lancashire, UK) for antigen retrieval, after which slides were allowed to cool at room temperature and were then washed in PBS. Subsequently, all sections were incubated in 5\% normal goat serum in PBS at $25^{\circ} \mathrm{C}$ for $30 \mathrm{~min}$ and in diluted rabbit anti-COX-2 (1:200, Cayman Chemical Company, Ann Arbor, MI, USA), mouse anti-Arc (activity-regulated cytoskeletal, 1:500; Santa Cruz Biotechnology, Inc., Dallas, TX, USA), rabbit anti-GluN1 ( $N$-methyl-d-aspartate receptor 1, 1:250; EMD Millipore, Billerica, MA, USA), rabbit anti-GluN2A/2B (1:100; EMD Millipore), and rabbit anti-pCREB (phosphorylated cAMP response element-binding protein, 1:400; Cell Signaling Technology, Inc., Danvers, MA, USA) antibodies at $4^{\circ} \mathrm{C}$ for $72 \mathrm{~h}$. Successively, the sections were treated with biotinylated goat anti-rabbit IgG antibody and a streptavidin-peroxidase complex (1:200; Vector Laboratories, Inc., Burlingame, CA, USA) for $2 \mathrm{~h}$ at $25^{\circ} \mathrm{C}$. All sections were visualized through the reaction with 3,3'-diaminobenzidine tetrachloride (Sigma; Merck KGaA) in a 0.1 M Tris-HCl buffer ( $\mathrm{pH}$ 7.2) and mounted on gelatin-coated slides. Sections were dehydrated and mounted in Canada balsam (Kanto, Tokyo, Japan).

Western blot analysis. To quantify the changes in COX-2 levels within the hippocampus, animals were euthanized at P1, 7, 14, 28 , and 56 ( $n=5$ per each group) and their brains were removed. Furthermore, tissues were dissected and processed for use in the western blot analysis, as described in a previous study (16). In brief, the hippocampus was dissected using a surgical blade and homogenized in $50 \mathrm{mM}$ PBS (pH 7.4) containing $0.1 \mathrm{mM}$ ethylene glycol-bis (2-aminoethylether)-N,N,N',N'-tetraacetic acid ( $\mathrm{pH} 8.0$ ), 0.2\% Nonidet P-40, $10 \mathrm{mM}$ ethylenediaminetetraacetic acid ( $\mathrm{pH} 8.0), 15 \mathrm{mM}$ sodium pyrophosphate, $100 \mathrm{mM}$ $\beta$-glycerophosphate, $50 \mathrm{mM} \mathrm{NaF}, 150 \mathrm{mM} \mathrm{NaCl}, 2 \mathrm{mM}$ sodium orthovanadate, $1 \mathrm{mM}$ phenylmethylsulfonyl fluoride, and $1 \mathrm{mM}$ dithiothreitol (DTT). After centrifugation, the protein levels in the supernatant were determined using a Micro BCA Protein assay kit according to the manufacturer's instructions (Pierce Chemical, Rockford, IL, USA). Aliquots containing $20 \mu \mathrm{g}$ of total protein were denatured by boiling in the loading buffer containing $150 \mathrm{mM}$ Tris ( $\mathrm{pH}$ 6.8), 3 mM DTT, 6\% sodium dodecyl sulfate, $0.3 \%$ bromophenol blue, and $30 \%$ glycerol and were then loaded onto a polyacrylamide gel. Successively to electrophoresis, proteins were transferred to nitrocellulose membranes (Pall Crop, East Hills, NY, USA), which were 
then blocked in 5\% non-fat dry milk in PBS/0.1\% Tween 20 for $45 \mathrm{~min}$, prior to incubation with a peroxidase-conjugated rabbit anti-COX-2 antibody (diluted 1:1,000). Detection was performed using the peroxidase-conjugated anti-rabbit IgG antibody (1:200; Vector Laboratories, Inc.) and an enhanced luminol-based chemiluminescent kit (Pierce Chemical). Blots were scanned and densitometry was conducted using the Scion Image software (Scion Corp., Frederick, MD, USA). Finally, they were stripped and reprobed with an antibody against $\beta$-actin as an internal loading control. Data were normalized to the $\beta$-actin level in each lane.

Data analysis. The analyses for COX-2 in both the hippocampal CA1/CA3 regions and the dentate gyrus and for GluN1 and GluN2A/2B in the dentate gyrus were performed using an image analysis system and the ImageJ software v. 1.50 (National Institutes of Health, Bethesda, MD, USA). Furthermore, data analysis was conducted under the same conditions by two observers for each experiment to ensure objectivity in the blind conditions, as described in a previous study (16). Digital images of the midpoint of the dentate gyrus were captured with a BX51 light microscope (Olympus, Tokyo, Japan) equipped with a digital camera (DP72, Olympus) connected to a computer monitor. Images were calibrated into an array of $512 \times 512$ pixels corresponding to a tissue area of 1,200x900 $\mu \mathrm{m}$ (x100 primary magnification). The resolution of each pixel was 256 gray levels, while the intensity of COX-2, GluN1, and GluN2A/2B pCREB immunoreactivity was evaluated by relative optical density (ROD), which was obtained after the transformation of the mean gray level using the following formula: $\mathrm{ROD}=\log$ (256/mean gray level). After determining the background staining ROD in unlabeled portions of the sections using the Photoshop CS6 software (Adobe Systems, Inc., San Jose, CA, USA), such a value was subtracted to correct for non-specific staining, using the ImageJ v. 1.50 software (National Institutes of Health). Data are expressed as a percentage of either P1 or the WT group (which was set at $100 \%$ ).

Additionally, Arc and pCREB immunoreactive nuclei in the whole dentate gyrus were counted with an analysis system equipped with a computer-based CCD camera (OPTIMAS software version 6.5; CyberMetrics ${ }^{\circledR}$ Corporation, Phoenix, AZ, USA; magnification, $\mathrm{x} 100$ ), as described in a previous study (11). Thereafter, the image was converted into a gray-scale image and Arc and pCREB immunoreactive nuclei were automatically selected according to the intensity of Arc and pCREB immunohistochemical staining, respectively.

Finally, tissue sections located at $90 \mu \mathrm{m}$ from each other were selected from an area between 1.82 and $2.30 \mathrm{~mm}$ posterior to the bregma, as defined by a mouse atlas (23). Cell counts and ROD were averaged using 5 sections from each WT and COX-2 KO mice.

Statistical analysis. The data were expressed as the mean of the experiments performed for each experimental investigation. To determine both the changes in COX-2 expression during postnatal development and the effects of COX-2 depletion on Arc, pCREB, GluN1, and GluN2A/2B, the mean differences among the groups were statistically analyzed through one-way analyses of variance followed by either the Bonferroni's post-hoc test or an unpaired student's t-test using the GraphPad Prism 5.01 software (GraphPad Software, Inc., La Jolla, CA, USA). The results were considered statistically significant when $\mathrm{P}<0.05$.

\section{Results}

Confirmation of COX-2 antibody specificity. Initially, COX-2 antibody specificity was assessed by COX-2 immunohistochemical analysis performed on COX-2 KO and WT mice. As a result, COX-2 immunoreactivity was found in both the stratum pyramidale of the $\mathrm{CA} 3$ region and the granule cell layer of the dentate gyrus in WT mice (Fig. 1A and B). In contrast, the same was not detected in COX-2 KO mice (Fig. 1C and D), who reported a significantly decreased COX-2 immunoreactivity in both the hippocampal CA3 region and the dentate gyrus when compared to WT mice (Fig. 1E).

\section{COX-2 immunoreactivity}

CA1 region: Although extremely weak COX-2 immunoreactivity was detected in the hippocampal CA1 region at P1 (Fig. 2A), it was observed in the stratum pyramidale of the $\mathrm{CA} 1$ region at $\mathrm{P} 7$ and $\mathrm{P} 14$, with an increase in intensity with age (Fig. 2B, C and F). In fact, strong COX-2 immunoreactivity was found in the stratum pyramidale of the $\mathrm{CA} 1$ region at P14. In contrast, it significantly decreased at P28 (Fig. 2F), during which it was only found in a few cells in the stratum pyramidale (Fig. 2D). However, COX-2 distribution pattern and immunoreactivity in the CA1 region at P56 was similar to those reported at P28 (Fig. 2E and F).

CA3 region: Although COX-2 immunoreactivity was weakly detected in the CA3 region at P1 (Fig. 3A), some strongly COX-2-immunoreactive cells were found at P7 in the outer layer of the stratum pyramidale (Fig. 3B), where COX-2 immunoreactivity was significantly increased compared to that at P1 (Fig. 3F). In concordance, strong COX-2 immunoreactive cells were found at P14 in most of the pyramidal cells in this region (Fig. 3C). However, COX-2 immunoreactivity was significantly decreased in the CA3 region at P28 compared to that seen at P14, although it was significantly higher than that found at either P1 or P7 (Fig. 3D and F). Finally, COX-2 distribution pattern and immunoreactivity at P56 were similar to those reported at P28 (Fig. 3E and F).

Dentate gyrus: Some COX-2 immunoreactivity was detected at P1 in the dentate gyrus (Fig. 4A). Furthermore, it was found in the outer granule cell layer of the dentate gyrus at both P7 (Fig. 4B) and P14 (Fig. 4C). Additionally, a significant age-dependent increase in COX-2 immunoreactivity was observed in the dentate gyrus at P14 (Fig. 4F). In contrast, COX-2 immunoreactivity was significantly decreased in the dentate gyrus at P28 compared to that seen at P14, while immunoreactive neurons were found in the inner half of the granule cell layer (Fig. 4D and F). However, COX-2 immunoreactivity was found in the inner granule cell layer at P56 and its expression levels were significantly increased in this region compared to those found at P28 and were similar to those seen at P14 (Fig. 4E and F).

COX-2 protein levels. Western blot analysis produced similar results, considering that the COX-2 protein levels in the 

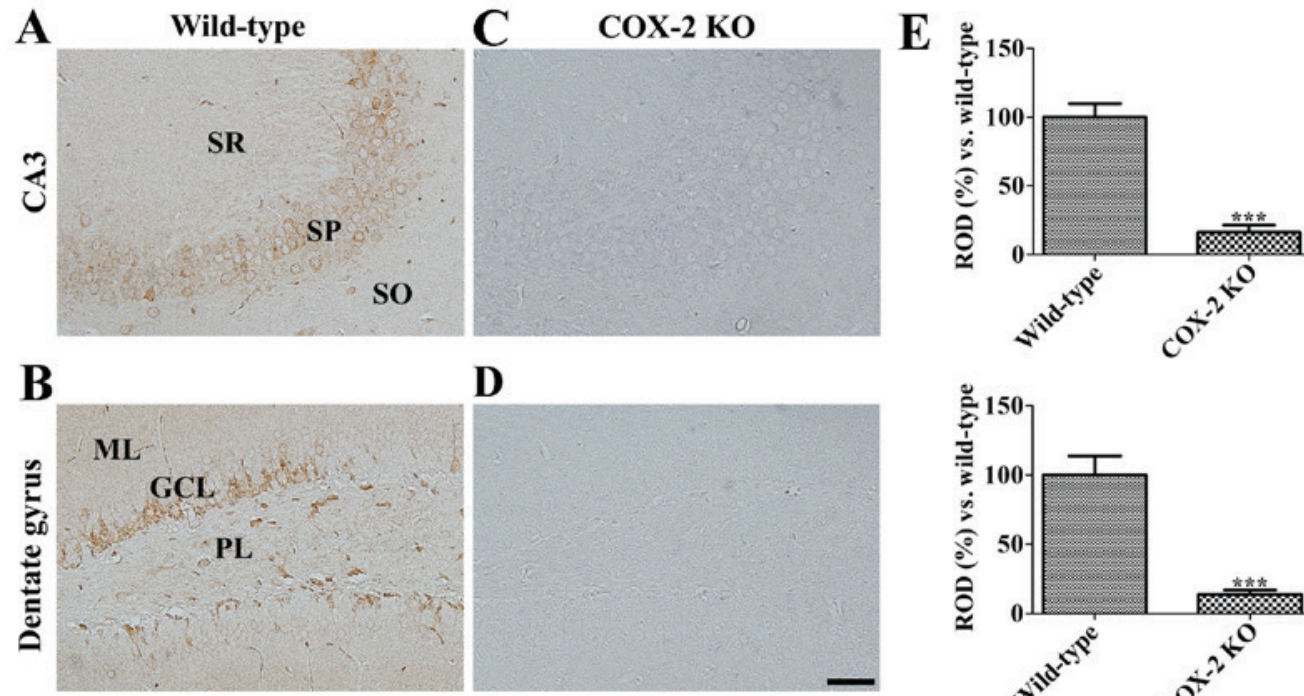

D

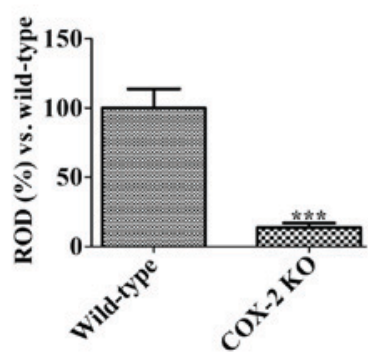

Figure 1. Immunohistochemical staining for cyclooxygenase-2 (COX-2) in the hippocampal CA3 region (A and C) and the dentate gyrus (B and D) of wild-type (WT) (A and B) and COX-2 KO (COX-2 KO, C and D) mice. COX-2 immunoreactivity is found in both the stratum pyramidale (SP) of the CA3 region and the granule cell layer (GCL) of the dentate gyrus in WT mice. Note that COX-2 immunoreactivity is not detected in these regions in COX-2 KO mice. SO, stratum oriens; SR, stratum radiatum; ML, molecular layer; PL, polymorphic layer. Scale bar=50 $\mu \mathrm{m}$. (E) Relative optical densities (ROD) are expressed as a percentage of the COX-2 immunoreactivity detected in WT mice in the dentate gyrus for each section ( $\mathrm{n}=5$ per group) ${ }^{* * *} \mathrm{P}<0.05$ vs. WT mice. All data are represented as the mean \pm standard error of the mean (SEM).

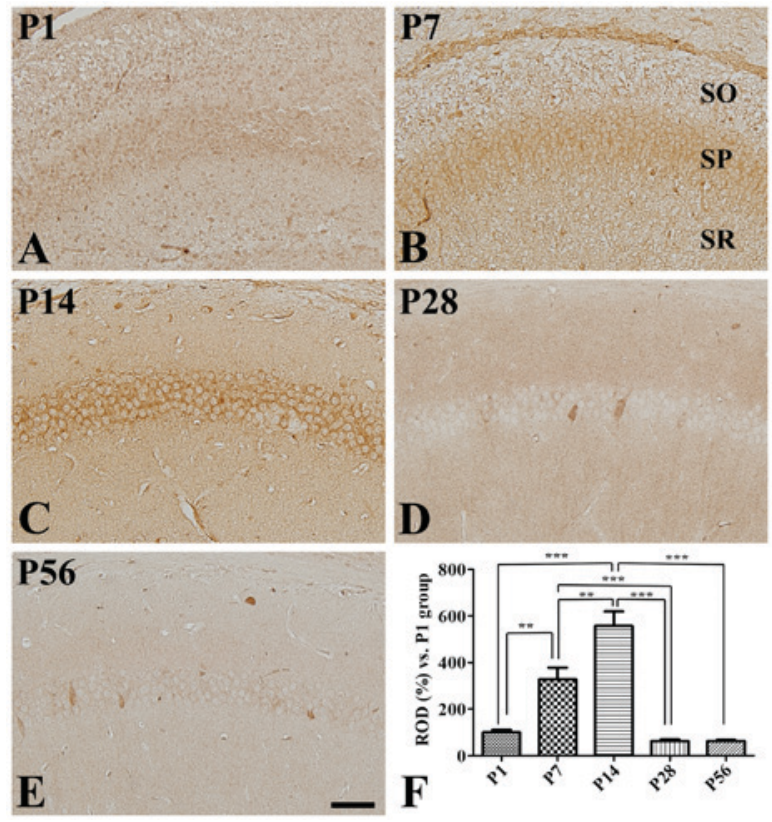

Figure 2. Immunohistochemical staining for cyclooxygenase-2 (COX-2) in the hippocampal CA1 region at (A) P1, (B) P7, (C) P14, (D) P28, and (E) P56. COX-2 immunoreactivity is found in the stratum pyramidale (SP) while COX-2 immunoreactive cells are prominent in this region at P14. SO, stratum oriens; SR, stratum radiatum. Scale bar $=50 \mu \mathrm{m}$. (F) Relative optical densities (ROD) are expressed as a percentage of the COX-2 immunoreactivity detected at $\mathrm{P} 1$ in the hippocampal $\mathrm{CA} 1$ region for each section ( $\mathrm{n}=5$ per group) ${ }^{* *} \mathrm{P}<0.01,{ }^{* * *} \mathrm{P}<0.001$. All data are represented as the mean \pm standard error of the mean (SEM).

hippocampal homogenates were significantly increased at P14 and decreased at both P28 and P56 (Fig. 5).

Effects of COX-2 depletion on the synaptic plasticity. While GluN1 immunoreactivity was observed in the granule cell layer

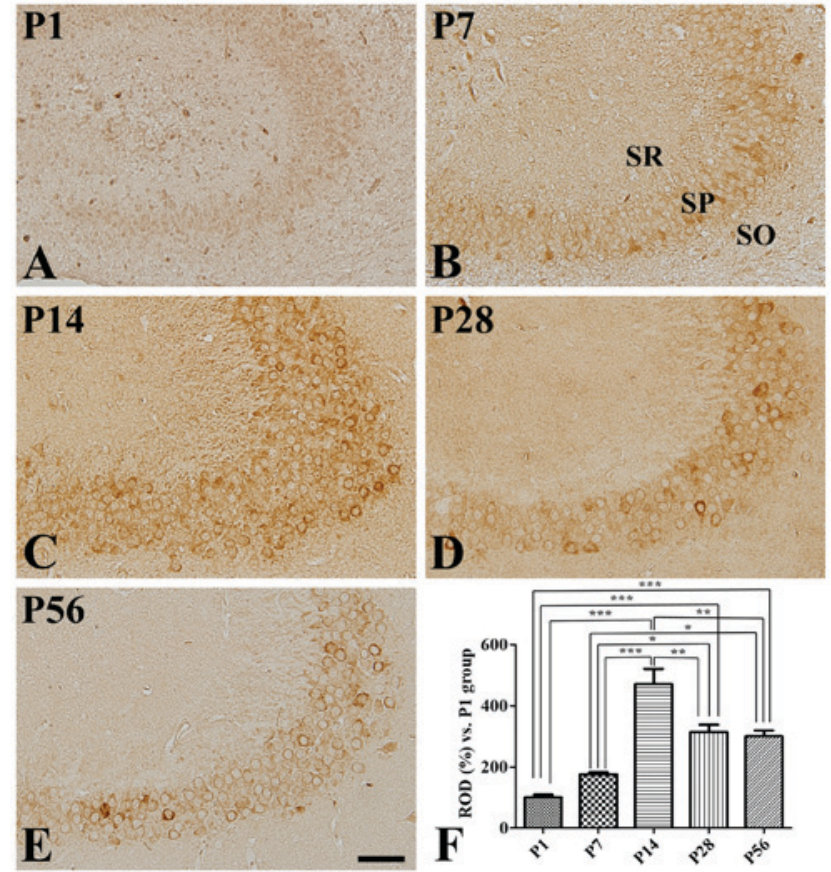

Figure 3. Immunohistochemical staining for cyclooxygenase-2 (COX-2) in the hippocampal CA3 region at (A) P1, (B) P7, (C) P14, (D) P28, and (E) P56. SO, stratum oriens; SP, stratum pyramidale; SR, stratum radiatum. Scale bar $=50 \mu \mathrm{m}$. (F) Relative optical densities (ROD) are expressed as a percentage of the COX-2 immunoreactivity detected at $\mathrm{P} 1$ in the hippocampal CA3 region for each section ( $\mathrm{n}=5$ per group) ${ }^{*} \mathrm{P}<0.05 ;{ }^{* * *} \mathrm{P}<0.01,{ }^{* * *} \mathrm{P}<0.001$. All data are represented as the mean \pm standard error of the mean (SEM).

of the dentate gyrus in WT mice (Fig. 6A), it was decreased in $\mathrm{KO}$ mice, although it was still observed (Fig. 6B and E).

In concordance, while GluN2A/2B immunoreactivity was mainly found in the polymorphic layer and the molecular layer of the dentate gyrus in WT mice (Fig. 6C), it was weakly 


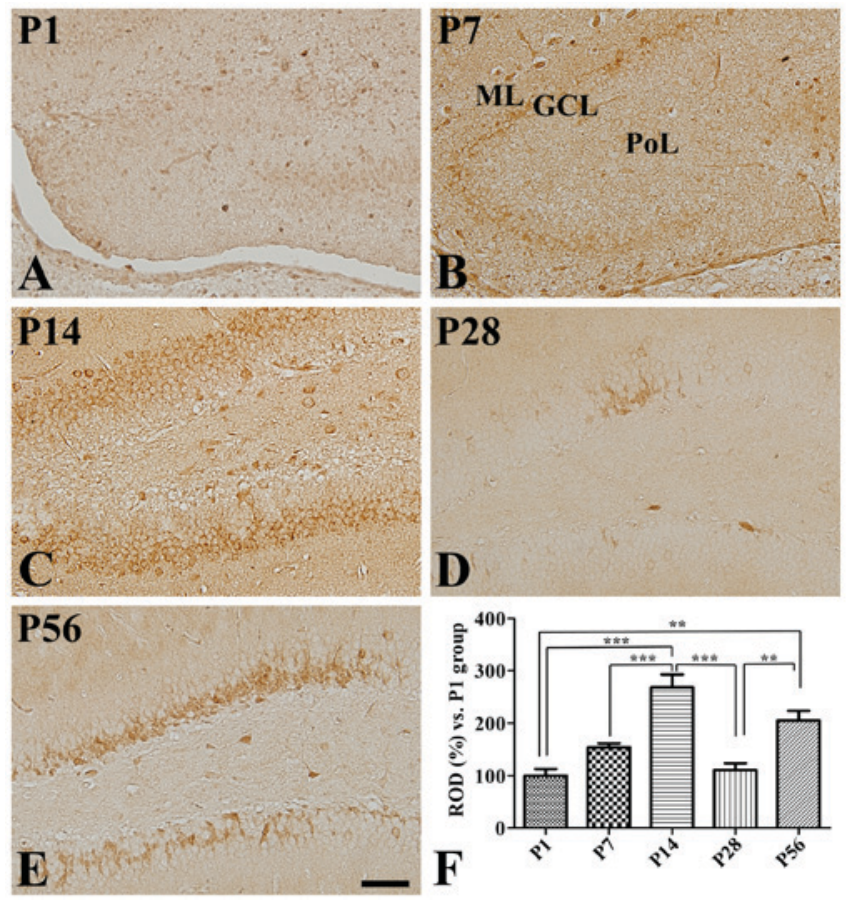

Figure 4. Immunohistochemical staining for cyclooxygenase-2 (COX-2) in the dentate gyrus at (A) P1, (B) P7, (C) P14, (D) P28, and (E) P56. COX-2 immunoreactivity is found in the outer granule cell layer (GCL) at both $\mathrm{P} 7$ and P14, whereas it is detected in the inner GCL at both P28 and P56. ML, molecular layer; PoL, polymorphic layer. Scale bar=50 $\mu \mathrm{m}$. (F) Relative optical densities (ROD) are expressed as a percentage of the COX-2 immunoreactivity detected at $\mathrm{P} 1$ in the dentate gyrus for each section $(\mathrm{n}=5$ per group) ${ }^{* *} \mathrm{P}<0.01,{ }^{* * * *} \mathrm{P}<0.001$. All data are represented as the mean \pm standard error of the mean (SEM).

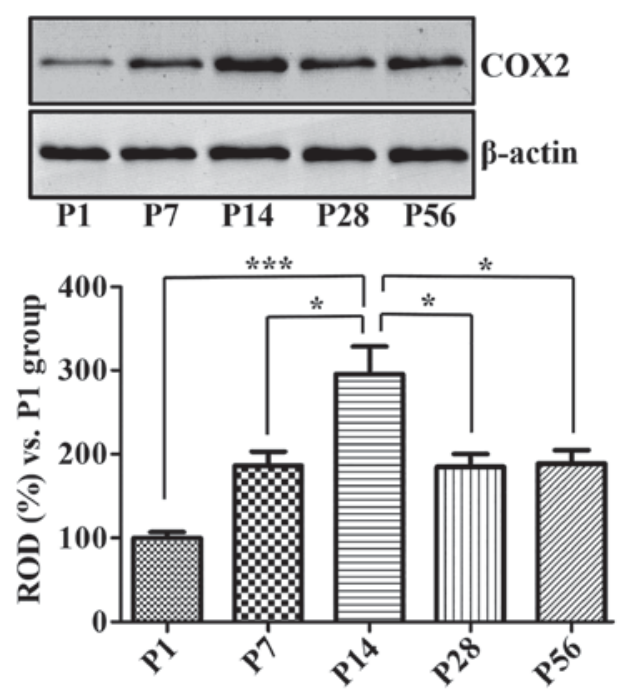

Figure 5. Western blot analysis expressed as a percentage of the value of the COX-2 immunoblot band at P1. Data were normalized to the $\beta$-actin level in each lane ( $\mathrm{n}=5$ per group) ${ }^{*} \mathrm{P}<0.05 ;{ }^{* * *} \mathrm{P}<0.001$. All data are represented as the mean \pm standard error of the mean (SEM).

detected in KO mice (Fig. 6D), given that it was significantly decreased (Fig. 6E).

Furthermore, although Arc immunoreactivity was observed in the granule cell layer of the dentate gyrus in WT mice (Fig. 7A), Arc immunoreactive cells were fewer in the dentate gyrus of KO mice than in that of WT mice (Fig. 7B).
In fact, the number of Arc immunoreactive cells in the dentate gyrus of KO mice was decreased by 55.5\% than that of WT mice (Fig. 7E).

Finally, several pCREB immunoreactive nuclei were detected in the subgranular zone of the dentate gyrus of WT mice (Fig. 7C); however, fewer pCREB immunoreactive nuclei were observed in the same area in KO mice (Fig. 7D), who reported the number of pCREB nuclei to be $41.3 \%$ of WT mice (Fig. 7E).

\section{Discussion}

Although the expression of COX-2, a rate-limiting enzyme involved in prostanoid synthesis, is upregulated in neurological disorders, such as ischemia and seizures, COX-2 is constitutively expressed in some brain regions, including the hippocampus. In the present study, we assessed COX-2 immunoreactivity and protein levels in the hippocampus considering that $\mathrm{COX}-2$ is correlated with the neuronal activity through the GluN $(14,15)$. Furthermore, we tested COX-2 antibody specificity based on the immunohistochemistry in the hippocampus using COX-2 KO mice. As a result, while COX-2 immunoreactivity was found in both the stratum pyramidale of the CA3 region and the granule cell layer of the dentate gyrus in WT mice, it nearly disappeared in KO mice. In the present study, we did not observe COX-2 immunoreactivity in either the dentate gyrus or the hippocampal CA 3 region at $\mathrm{P} 7$. This result is supported by previous studies on rats that showed extremely little COX-2 expression immediately after birth (20-22). Additionally, we observed a significant increase in COX-2 immunoreactivity at P14 in these regions compared to P7. This result is in concordance with previous studies reporting that COX-2 is primarily expressed in neurons of intact animals, although it is inducible by inflammation $(15,24,25)$. Moreover, a greater than twofold increase in constitutive COX-2 mRNA expression was observed in both the granule cell layer of the dentate gyrus and the CA3 hippocampal region by P21, identifying COX-2 adult levels (22). Conflict evidence was demonstrated that COX-2 mRNA levels were similarly detected by $\mathrm{P} 11$ in the hippocampus (26). In fact, in the rat cerebral cortex, COX-2 expression increases two- to threefold between P14 and P30 when compared to P7 (20), while no significant COX-2 mRNA expression was found in the cortex by P11 (26). In addition, we found COX-2 immunoreactivity in the hippocampal subregions of the mouse brain and we observed that COX-2 expression peaked in the hippocampus at P14 to decrease again at P28 and P56. This result is supported by a previous study suggesting that COX-2 expression peaks during the second postnatal week (27). However, most studies have been investigated constitutive COX-2 mRNA expression, not protein expression in the hippocampus during postnatal development. Furthermore, although we previously demonstrated that doublecortin-positive neuroblasts are abundantly detected in the somatosensory cortex by P14 and rarely detected at P21 (4), we observed differential localization of COX-2 with age between P7 and P56, shifting from the outer to the inner granule cell layer.

Arc (activity-regulated cytoskeleton-associated protein) is known to be rapidly up-regulated by external stimuli in excitatory projection neurons to induce neural plasticity (28-30) 

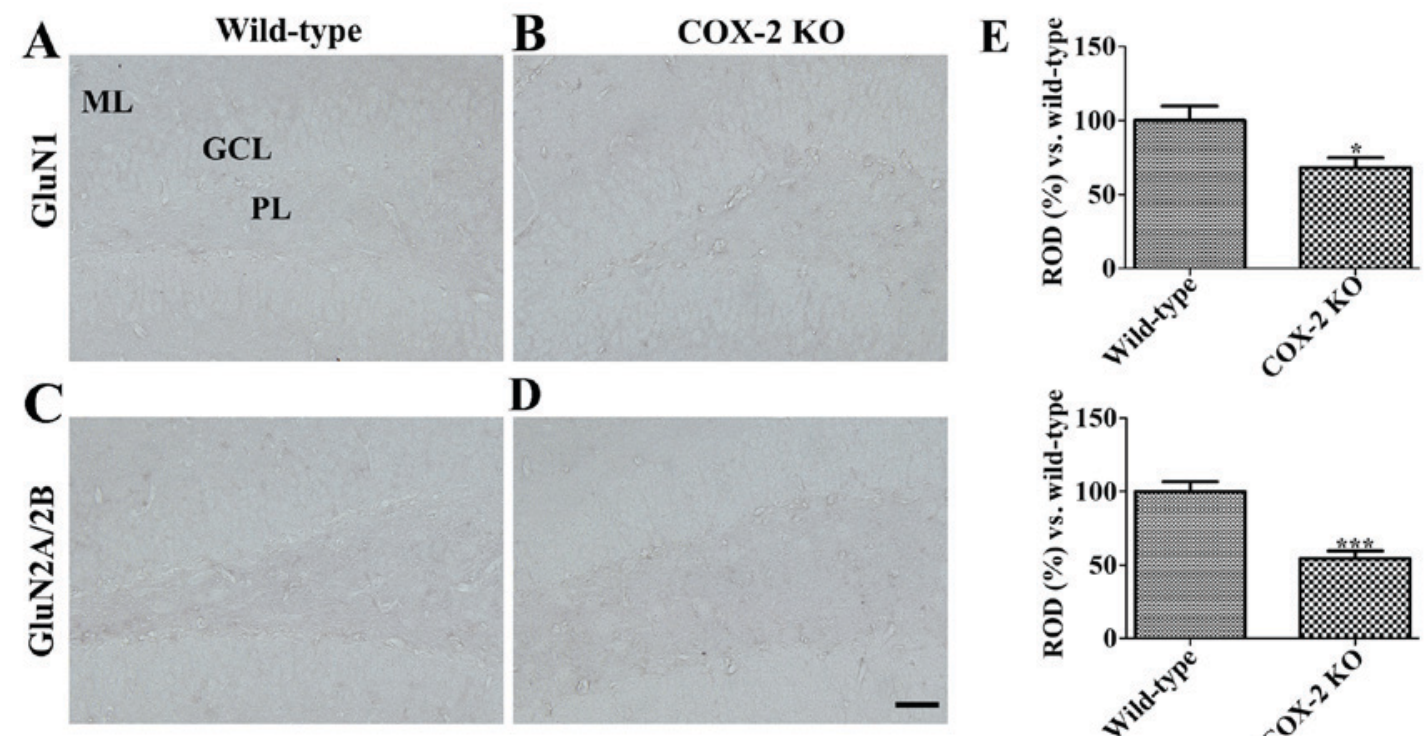

D

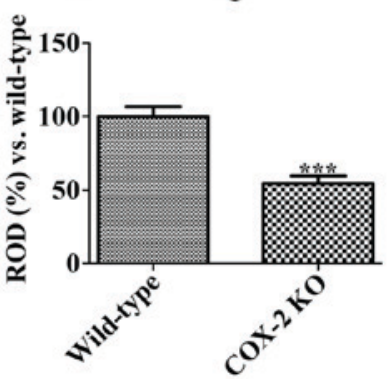

Figure 6. Immunohistochemical staining for $N$-methyl-d-aspartate receptor 1 (GluN1, A and B) and GluN2A/2B (C and D) in the dentate gyrus of wild-type (WT) (A and C) and cyclooxygenase-2 (COX-2) KO (B and D) mice. In WT mice, GluN1 immunoreactivity is observed in the granule cell layer (GCL), while GluN2A/2B immunoreactivity is found in both the polymorphic layer (PoL) and the molecular layer (ML). Note that GluN1 and GluN2A/2B immunoreactivity is weakly detected in COX-2 KO mice. (E) Scale bar=50 $\mu \mathrm{m}$. Relative optical densities (ROD) are expressed as a percentage of the GluN1 and GluN2A/2B immunoreactivity detected in the dentate gyrus of WT mice for each section ( $\mathrm{n}=5$ per group) ${ }^{*} \mathrm{P}<0.05 ;{ }^{* * * *} \mathrm{P}<0.001$. All data are represented as the mean \pm standard error of the mean (SEM).
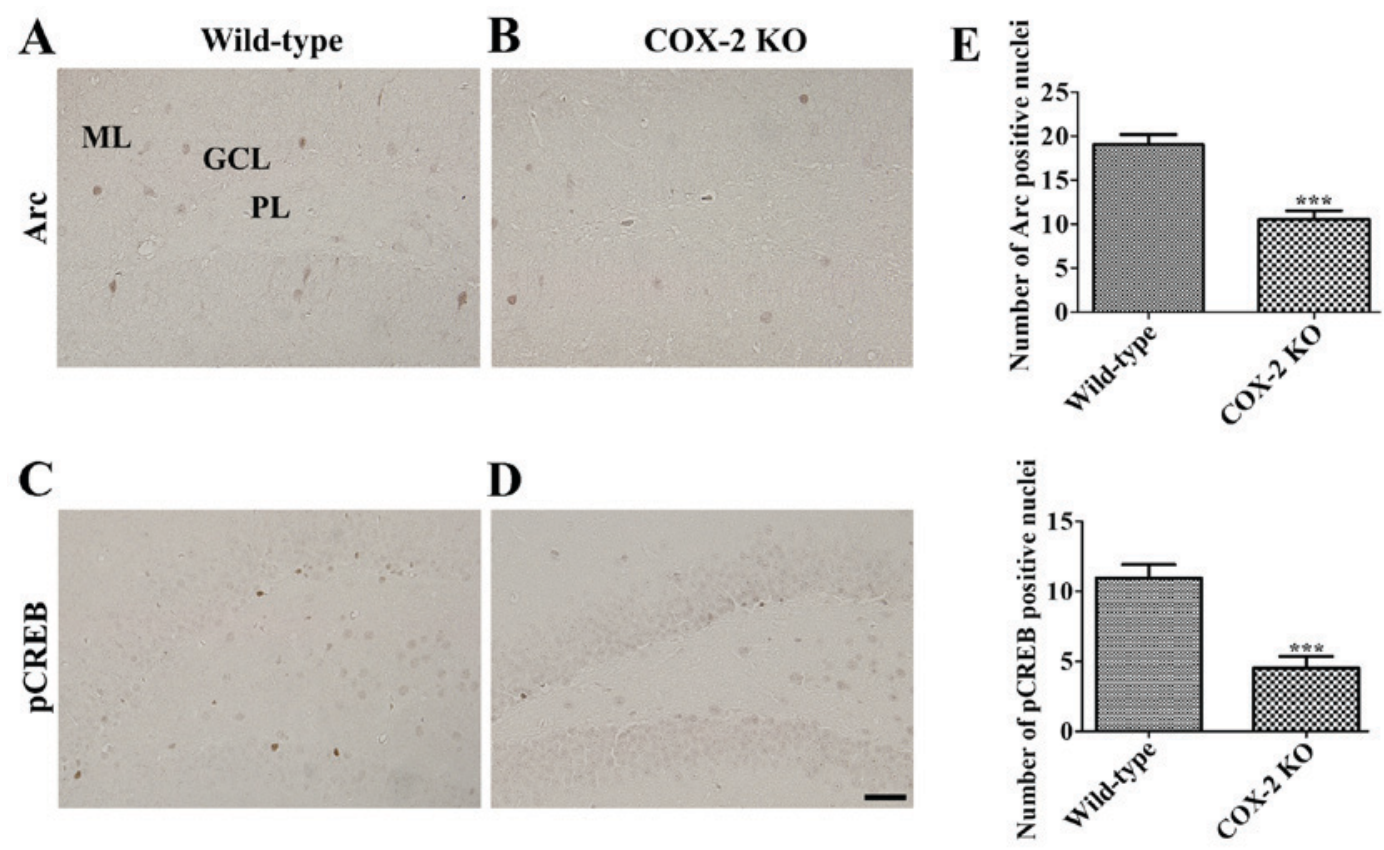

Figure 7. Immunohistochemical staining for Arc (A and B) and pCREB (C and D) in the dentate gyrus of wild-type (WT) (A and C) and cyclooxygenase-2 (COX-2) KO (B and D) mice. Arc positive nuclei are detected in the granule cell layer (GCL) of the dentate gyrus whereas pCREB immunoreactive nuclei are found in the subgranular zone of the dentate gyrus. Note that Arc and pCREB positive nuclei are fewer in the dentate gyrus of COX-2 KO mice compared to those of WT mice. Scale bar=50 $\mu \mathrm{m}$. (E) The number of Arc and pCREB immunoreactive neurons in each group per section is shown (n=5 per group) ${ }_{* * * * *} \mathrm{P}<0.001$ vs. WT mice. All data are represented as the mean \pm standard error of the mean (SEM).

and is a factor established to be responsible for modulating memory consolidation in a GluNs activation-dependent manner $(28,31,32)$. Arc is also closely related to adult neurogenesis in the hippocampus $(33,34)$. To elucidate the role of COX-2 on hippocampal synaptic plasticity, we investigated Arc expression in the hippocampus of COX-2 KO and WT mice. As a result, we observed Arc expression in the granule cell layer of the dentate gyrus and found the number of Arc-positive nuclei to be significantly decreased in the dentate gyrus of COX-2 KO mice compared to that of WT mice. This result suggests that COX-2 plays an important role in the synaptic plasticity of the dentate gyrus. Furthermore, these COX-2 changes may be associated with the first-time space navigation ability of mice after birth. In fact, Langston et al (35) demonstrated that 
strong directional tuning was already apparent at P15 and P16 in pups exploring for the first time the outside of their nest. Considering that both COX-2 (36) and Arc (29) are coupled to neural activity in the hippocampus, hippocampal neural activity is strongly coupled to navigation through the firing of place cells.

Hippocampal GluNs are primarily composed of the GluN1 and GluN2A or GluN2B subunits. In the current study, we observed a reduction in GluN1 and GluN2A/2B immunoreactivity in the hippocampal dentate gyrus of $\mathrm{COX}-2 \mathrm{KO}$ mice compared to that seen in WT mice. This result suggests that COX-2 has a role in modulating the basal levels of GluN1 and GluN2A/2B in the hippocampus. While GluN stimulation activates CREB and BDNF expression, extrasynaptic GluN stimulation decreases it (37-39). Furthermore, GluN participates in the formation of neuronal spines and facilitates the proliferation of cells into neurons (40). GluN1 transgenic mice were shown to report increases in proliferating neural progenitor cells in the adult sugranular zone of dentate gyrus (41), whereas GluN2A KO mice were described to present better exercise-induced amelioration of proliferating neural progenitor cells compared to WT mice (42). In addition, GluN1 null mutant embryo, COX-2 mRNA expression was significantly decreased compared to that in the wide-type embryo (43). Therefore, the reduction in GluN1 and GluN2A/2B observed in COX-2 KO mice may be closely associated with decreases in both the proliferating activity and synaptic plasticity.

Moreover, we observed the effects of COX-2 depletion on pCREB expression in the hippocampus given that GluNs stimulation increases pCREB levels, acquiring a neuroprotective role (38). In addition, activation of both the GluNs and BDNF signaling pathways can activate the phosphorylation of CREB at Ser133 (pCREB), which is a rate-limiting step in CREB signaling (44). Our results reported that COX-2 depletion significantly decreased pCREB immunoreactive nuclei in the subgranular zone of the dentate gyrus of $\mathrm{KO}$ mice compared to the age-matched WT mice. This result is consistent with a previous study indicating that genetic and pharmacological inhibition of COX-2 prominently decreased the number of pCREB-immunoreactive nuclei in the dentate gyrus (17-19). In addition, luciferase assay demonstrated that CREB was involved in the constitutive expression of COX-2 in neurons (43).

Another possible reason behind such a phenomenon may be that COX-2 plays a role in the Wnt-5a-dependent regulation of the hippocampal synaptic structure and function; specifically, Wnt-5a targets COX-2 via microRNA-101b (45) and has a key role in both the synaptic structure and function of the adult nervous system $(46,47)$. In addition, COX-2 is associated with stress-related functions in the brain, as endogenous glucocorticoids modulate the levels of COX-2 and its downstream target (i.e., microsomal PGE synthase-1) under conditions of stress (48). Furthermore, blockade of the $\mathrm{PGE}_{2}$ receptor 2 as well as COX-2 significantly reduces the number of neural progenitor cells in the dentate gyrus (49). However, more studies need to be elucidated about the changes of proteins related to synaptic plasticity. Overall, the modulation of COX-2 is closely related with the synaptic plasticity in postnatal development and hippocampal neurogenesis in adult brain. Long-term treatment of COX-2 inhibitor may reduce the basal levels of hippocampal neurogenesis and synaptic plasticity in the naïve young and adult brain.

In conclusion, COX-2 is constitutively expressed in both the granule cells of the dentate gyrus and the pyramidal cells of the hippocampal CA1-3 regions at P14, although it thereafter decreases. In particular, the localization of COX-2 expression shifts from the outer to the inner granule cell layer of the dentate gyrus with age. Furthermore, COX-2 depletion significantly decreases the expression of synaptic markers, including Arc, GluN1, GluN2A/2B, and pCREB, in the hippocampal dentate gyrus. Overall, constitutively expressed COX-2 may be associated with synaptic plasticity in the hippocampus during postnatal development.

\section{Acknowledgements}

Not applicable.

\section{Funding}

This study was supported by the National Research Foundation of Korea (NRF) grant funded by the Korea Government (Ministry of Science, ICT and Future Planning) (grant no. NRF-2016R1A2B4009156) and by the Korea Mouse Phenotyping Project (grant nos.NRF-2015M3A9D5A01076747). In addition, this work was supported by the Promising-Pioneering Researcher Program through Seoul National University (SNU) in 2015 and by the Research Institute for Veterinary Science, Seoul National University.

\section{Availability of data and materials}

The datasets generated and/or analyzed during the current study are available from the corresponding author on reasonable request.

\section{Authors' contributions}

HYJ and IKH designed the experiments and the study. HYJ, DYY, SMN, JWK, WK, KYL and JHC looked after the animals and performed the morphological experiments. HJK and DWK conducted western blot analysis. YSY and JKS participated in designing and discussing the study. HYJ and IKH wrote this manuscript. All authors read and approved the final manuscript.

\section{Ethics approval and consent to participate}

Animal handling and care conformed to the guidelines established by the current international laws and policies [National Institutes of Health (NIH) Guide for the Care and Use of Laboratory Animals; NIH Publication no. 85-23, 1985, revised 2011], and were approved by both the Institutional Animal Care and Use Committee (IACUC) of Seoul National University (approval no.: SNU-120210-1 and SNU-140313-1) and Kangwon National University (approval no.: KW-161226-1).

\section{Patient consent for publication}

Not applicable. 


\section{Competing interests}

The authors declare that they have no competing interests.

\section{References}

1. Isaacson RL and Pribram KH (eds): The Hippocampus. Vols. 3 and 4. Plenum, New York, 1985.

2. Bayer SA: Development of the hippocampal region in the rat. II. Morphogenesis during embryonic and early postnatal life. J Comp Neurol 190: 115-134, 1980.

3. Schlessinger AR, Cowan WM and Gottlieb DI: An autoradiographic study of the time of origin and the pattern of granule cel migration in the dentate gyrus of the rat. J Comp Neurol 159: 149-175, 1975.

4. Yoo DY, Yoo KY, Choi JW, Kim W, Lee CH, Choi JH, Park JH, Won MH and Hwang IK: Time course of postnatal distribution of doublecortin immunoreactive developing/maturing neurons in the somatosensory cortex and hippocampal CA1 region of C57BL/6 mice. Cell Mol Neurobiol 31: 729-736, 2011.

5. Jung HY, Yim HS, Yoo DY, Kim JW, Chung JY, Seong JK, Yoon YS, Kim DW and Hwang IK: Postnatal changes in glucose transporter 3 expression in the dentate gyrus of the C57BL/6 mouse model. Lab Anim Res 32: 1-7, 2016.

6. Yoo DY, Yoo KY, Park JH, Choi JW, Kim W, Hwang IK and Won MH: Detailed differentiation of calbindin D-28k-immunoreactive cells in the dentate gyrus in C57BL/6 mice at early postnatal stages. Lab Anim Res 27: 153-159, 2011.

7. Kujubu DA, Fletcher BS, Varnum BC, Lim RW and Herschman HR: TIS10, a phorbol ester tumor promoter-inducible mRNA from Swiss 3T3 cells, encodes a novel prostaglandin synthase/cyclooxygenase homologue. J Biol Chem 266: 12866-12872, 1991 .

8. O'Banion MK, Winn VD and Young DA: cDNA cloning and functional activity of a glucocorticoid-regulated inflammatory cyclooxygenase. Proc Natl Acad Sci USA 89: 4888-4892, 1992.

9. Yagami T, Koma H and Yamamoto Y: Pathophysiological roles of cyclooxygenases and prostaglandins in the central nervous system. Mol Neurobiol 53: 4754-4771, 2016.

10. Sang N, Zhang J, Marcheselli V, Bazan NG and Chen C: Postsynaptically synthesized prostaglandin E2 (PGE2) modulates hippocampal synaptic transmission via a presynaptic PGE2 EP2 receptor. J Neurosci 25: 9858-9870, 2005.

11. Endres M, Dirnagl U and Moskowitz MA: The ischemic cascade and mediators of ischemic injury. Handb Clin Neurol 92: 31-41, 2009.

12. Iadecola C, Niwa K, Nogawa S, Zhao X, Nagayama M, Araki E, Morham S and Ross ME: Reduced susceptibility to ischemic brain injury and N-methyl-D-aspartate-mediated neurotoxicity in cyclooxygenase-2-deficient mice. Proc Natl Acad Sci USA 98: 1294-1299, 2001.

13. Kirkby NS, Zaiss AK, Urquhart P, Jiao J, Austin PJ, Al-Yamani M, Lundberg MH, MacKenzie LS, Warner TD, Nicolaou A, et al: LC-MS/MS confirms that COX-1 drives vascular prostacyclin whilst gene expression pattern reveals non-vascular sites of COX-2 expression. PLoS One 8: e69524, 2013.

14. Hewett SJ, Bell SC and Hewett JA: Contributions of cyclooxygenase- 2 to neuroplasticity and neuropathology of the central nervous system. Pharmacol Ther 112: 335-357, 2006.

15. Yamagata K, Andreasson KI, Kaufmann WE, Barnes CA and Worley PF: Expression of a mitogen-inducible cyclooxygenase in brain neurons: Regulation by synaptic activity and glucocorticoids. Neuron 11: 371-386, 1993.

16. Jung HY, Yoo DY, Kim JW, Kwon HJ, Lee KY, Choi JH, Kim DW, Chung JY, Yoon YS and Hwang IK: Age-associated alterations in constitutively expressed cyclooxygenase- 2 immunoreactivity and protein levels in the hippocampus. Mol Med Rep 15: 4333-4337, 2017.

17. Hwang IK, Yi SS, Yoo KY, Park OK, Yan B, Kim IY, Kim YN, Song W, Moon SM, Won MH, et al: Effects of treadmill exercise on cyclooxygenase- 2 in the hippocampus in type 2 diabetic rats: Correlation with the neuroblasts. Brain Res 1341: 84-92, 2010.

18. Nam SM, Kim JW, Yoo DY, Choi JH, Kim W, Jung HY, Won MH, Hwang IK, Seong JK and Yoon YS: Effects of treadmill exercise on neural stem cells, cell proliferation, and neuroblast differentiation in the subgranular zone of the dentate gyrus in cyclooxygenase-2 knockout mice. Neurochem Res 38: 2559-2569, 2013
19. Nam SM, Kim JW, Yoo DY, Choi JH, Kim W, Jung HY, Won MH, Hwang IK, Seong JK and Yoon YS: Comparison of pharmacological and genetic inhibition of cyclooxygenase-2: Effects on adult neurogenesis in the hippocampal dentate gyrus. J Vet Sci 16: 245-251, 2015.

20. Hickey RW, Adelson PD, Johnnides MJ, Davis DS, Yu Z, Rose ME, Chang YF and Graham SH: Cyclooxygenase-2 activity following traumatic brain injury in the developing rat. Pediatr Res 62: 271-276, 2007

21. Kaufmann WE, Worley PF, Taylor CV, Bremer M and Isakson PC: Cyclooxygenase-2 expression during rat neocortical development and in Rett syndrome. Brain Dev 19: 25-34, 1997.

22. Tocco G, Freire-Moar J, Schreiber SS, Sakhi SH, Aisen PS and Pasinetti GM: Maturational regulation and regional induction of cyclooxygenase-2 in rat brain: Implications for Alzheimer's disease. Exp Neurol 144: 339-349, 1997.

23. Paxinos G and Franklin KBJ: The Mouse Brain in Stereotaxic Coordinates. Academic Press, San Diego, 2001.

24. Breder CD, Dewitt D and Kraig RP: Characterization of inducible cyclooxygenase in rat brain. J Comp Neurol 355: 296-315, 1995.

25. Breder CD: Cyclooxygenase systems in the mammalian brain. Ann NY Acad Sci 813: 296-301, 1997.

26. Piscopo P, Bernardo A, Calamandrei G, Venerosi A, Valanzano A, Bianchi D, Confaloni A and Minghetti L: Altered expression of cyclooxygenase-2, presenilins and oxygen radical scavenging enzymes in a rat model of global perinatal asphyxia. Exp Neurol 209: 192-198, 2008.

27. Zhang MZ, Wang JL, Cheng HF, Harris RC and McKanna JA: Cyclooxygenase-2 in rat nephron development. Am J Physiol 273: F994-F1002, 1997.

28. Bloomer WA, VanDongen HM and VanDongen AM: Arc/Arg3.1 translation is controlled by convergent N-methyl-D-aspartate and Gs-coupled receptor signaling pathways. J Biol Chem 283: 582-592, 2008

29. Guzowski JF, McNaughton BL, Barnes CA and Worley PF: Environment-specific expression of the immediate-early gene Arc in hippocampal neuronal ensembles. Nat Neurosci 2: 1120-1124, 1999

30. Guzowski JF, Lyford GL, Stevenson GD, Houston FP, McGaugh JL, Worley PF and Barnes CA: Inhibition of activity-dependent arc protein expression in the rat hippocampus impairs the maintenance of long-term potentiation and the consolidation of long-term memory. J Neurosci 20: 3993-4001, 2000.

31. Holloway CM and McIntyre CK: Post-training disruption of Arc protein expression in the anterior cingulate cortex impairs long-term memory for inhibitory avoidance training. Neurobiol Learn Mem 95: 425-432, 2011.

32. Steward O and Worley P: Local synthesis of proteins at synaptic sites on dendrites: Role in synaptic plasticity and memory consolidation? Neurobiol Learn Mem 78: 508-527, 2002.

33. Kuipers SD, Trentani A, Tiron A, Mao X, Kuhl D and Bramham CR: BDNF-induced LTP is associated with rapid Arc/Arg3.1-dependent enhancement in adult hippocampal neurogenesis. Sci Rep 6: 21222, 2016.

34. Meconi A, Lui E and Marrone DF: Sustained Arc expression in adult-generated granule cells. Neurosci Lett 603: 66-70, 2015.

35. Langston RF, Ainge JA, Couey JJ, Canto CB, Bjerknes TL, Witter MP, Moser EI and Moser MB: Development of the spatial representation system in the rat. Science 328: 1576-1580, 2010.

36. Kaufmann WE, Worley PF, Pegg J, Bremer M and Isakson P: COX-2, a synaptically induced enzyme, is expressed by excitatory neurons at postsynaptic sites in rat cerebral cortex. Proc Natl Acad Sci USA 93: 2317-2321, 1996.

37. Hardingham GE, Fukunaga Y and Bading H: Extrasynaptic NMDARs oppose synaptic NMDARs by triggering CREB shut-off and cell death pathways. Nat Neurosci 5: 405-414, 2002.

38. Hardingham GE and Bading H: Synaptic versus extrasynaptic NMDA receptor signalling: Implications for neurodegenerative disorders. Nat Rev Neurosci 11: 682-696, 2010.

39. Parsons MP and Raymond LA: Extrasynaptic NMDA receptor involvement in central nervous system disorders. Neuron 82: 279-293, 2014.

40. Nacher J and McEwen BS: The role of N-methyl-D-aspartate receptors in neurogenesis. Hippocampus 16: 267-270, 2006.

41. Bursztajn S, Falls WA, Berman SA and Friedman MJ: Cell proliferation in the brains of NMDAR NR1 transgenic mice. Brain Res 1172: 10-20, 2007. 
42. Kitamura T, Mishina M and Sugiyama H: Enhancement of neurogenesis by running wheel exercises is suppressed in mice lacking NMDA receptor epsilon 1 subunit. Neurosci Res 47: 55-63, 2003.

43. Hewett SJ, Shi J, Gong Y, Dhandapani K, Pilbeam C and Hewett JA: Spontaneous glutamatergic synaptic activity regulates constitutive COX-2 expression in neurons: Opposing roles for the transcription factors CREB (cAMP response element binding) protein and Sp1 (stimulatory protein-1). J Biol Chem 291: 27279-27288, 2016.

44. Gonzalez GA, Yamamoto KK, Fischer WH, Karr D, Menzel P, Biggs W III, Vale WW and Montminy MR: A cluster of phosphorylation sites on the cyclic AMP-regulated nuclear factor CREB predicted by its sequence. Nature 337: 749-752, 1989.

45. Codocedo JF and Inestrosa NC: Wnt-5a-regulated miR-101b controls COX2 expression in hippocampal neurons. Biol Res 49: 9, 2016.

46. Bian WJ, Miao WY, He SJ, Wan ZF, Luo ZG and Yu X: A novel Wnt5a-Frizzled 4 signaling pathway mediates activity-independent dendrite morphogenesis via the distal PDZ motif of Frizzled 4. Dev Neurobiol 75: 805-822, 2015.
47. Farías GG, Alfaro IE, Cerpa W, Grabowski CP, Godoy JA, Bonansco C and Inestrosa NC: Wnt-5a/JNK signaling promotes the clustering of PSD-95 in hippocampal neurons. J Biol Chem 284: 15857-15866, 2009.

48. Ma Y, Matsuwaki T, Yamanouchi $\mathrm{K}$ and Nishihara $\mathrm{M}$ Cyclooxygenase-2-related signaling in the hypothalamus plays differential roles in response to various acute stresses. Brain Res 1508: 23-33, 2013.

49. Ma Y, Matsuwaki T, Yamanouchi $\mathrm{K}$ and Nishihara M: Glucocorticoids suppress the protective effect of Cyclooxygenase-2-related signaling on hippocampal neurogenesis under acute immune stress. Mol Neurobiol 54: 1953-1966, 2017.

This work is licensed under a Creative Commons Attribution-NonCommercial-NoDerivatives 4.0 International (CC BY-NC-ND 4.0) License. 